\title{
Chances and Limitations in the Application of Laser Chemical Machining for the Manufacture of Micro Forming Dies
}

\author{
Hamza Messaoudi ${ }^{1, *}$, Florian Böhmermann ${ }^{2}$, Merlin Mikulewitsch ${ }^{3}$, Axel von Freyberg ${ }^{3}$, Andreas Fischer $^{3}$, \\ Oltmann Riemer ${ }^{2}$, and Frank Vollertsen ${ }^{1,4}$ \\ ${ }^{1}$ BIAS - Bremer Institut für angewandte Strahltechnik, Bremen, Germany \\ ${ }^{2}$ Leibniz Institute for Materials Engineering, Laboratory for Precision Machining LFM, Bremen, Germany \\ ${ }^{3}$ University of Bremen, BIMAQ - Bremen Institute for Metrology, Automation and Quality Science, Bremen, Germany \\ ${ }^{4}$ University of Bremen, Faculty of Production Engineering-Mechanical Engineering \& Process Engineering, Bremen, Germany
}

\begin{abstract}
Laser chemical machining, a non-conventional processing method based on thermally activated electrochemical material dissolution, represents a promising technology for manufacturing metallic dies for micro forming applications. Prior to widespread industrial acceptance the machining quality of laser chemical machining should be characterized. For this purpose, laser chemical machining is compared with micro milling regarding both the dimensional accuracy and the surface quality. Therefore, square micro cavities exhibiting side walls between $100 \mu \mathrm{m}$ and $400 \mu \mathrm{m}$ in length and $60 \mu \mathrm{m}$ in depth are machined with both manufacturing processes into the cobalt-chrome alloy Stellite 21. The geometrical features are investigated using laser-scanning confocal microscopy and scanning electron microscopy. On the one hand, laser chemical machining is more suitable for manufacturing cavities with dimensions $<200 \mu \mathrm{m}$ due to higher shape accuracy with stable mean edge radii of $(11.2 \pm 1.3) \mu \mathrm{m}$ as a result of roughing and finishing steps. On the other hand, the finish quality of micro milling with mean surface roughness $S a$ of $0.2 \mu$ m could not be achieved with laser chemical machining due to in-process induced waviness. Finally, the metallographic analysis of the surface-near layers reveals that both manufacturing processes ensure gentle machining without any noticeable micro structural impact.
\end{abstract}

Keywords: Micro machining, Machine tool, Quality

\section{Introduction}

Manufacturing of metallic parts by micro forming is a key approach to meet the ever-increasing demand for micro mechanical and micro electrical components, required for, e.g., consumer products or biomedical devices. Forming dies applied to the manufacture of those components usually exhibit geometrical features of several tenths of micrometers with tolerances in the submicrometer range [1]. Therefore, the achievable dimensional accuracy as well as the resulting surface roughness represent crucial figures of merit for micro forming processes [2].

Moreover, tool materials for forming processes require appropriate ductility combined with high hardness and wear resistance [3]. These include mono crystals (e.g. sapphire) as well as ceramic materials (e.g. alumina, zirconia etc.) and cemented carbides (e.g. tungsten or titanium carbide), which are characterized by complex, time- and cost-intensive production procedures. Besides, metallic alloys such as iron-, nickel- and cobalt-based alloys represent widely used alternative materials. However, the manufacture of micro forming tools from the mentioned alloys is still challenging due to additionally occurring size effects in the microscale [4].

Using conventional machining like milling and turning, which are based on mechanical material removal, the hardness of applied tools should significantly exceed that of the machined material. Thereby, the induced thermomechanical loads can induce additional residual stresses and change the micro structure in the surface-near layers. Thus, the chemical inertia as well the stability could be limited [5]. For forming dies exhibiting geometries or features smaller than $1 \mathrm{~mm}$ micro milling is widely used, especially in mold manufacturing, due to its high removal rates (some $\mathrm{mm}^{3} / \mathrm{min}$ ) and its excellent surface finish [6]. To ensure high surface quality fine grained tool steels with dispersed carbides are used. Thus, a surface roughness $R a$ of some $10 \mathrm{~nm}$ can be realized. Nevertheless, micro milling is limited regarding the dimensional accuracy and the surface finish; especially when tools of $\leq 0.2 \mathrm{~mm}$ in diameter are applied. This can be explained by the incidence of ploughing effects and feed marks [6].

\footnotetext{
Corresponding author: messaoudi@bias.de
} 
Alternatively, hard materials can be manufactured using non-conventional machining. Among others this includes laser machining and electrochemical machining (ECM) [7]. Laser machining, based on material ablation, is characterized by an increased machining precision and quality with shorter laser pulses. However, as the removal rate and the processing quality are reciprocal, the economic use of ultrashort pulsed lasers is still inefficient due time- and the high procurement costs and the low removal rates (typically $10^{-3} \mathrm{~mm}^{3} / \mathrm{min}$ ) [8]. Besides, ECM is characterized by its smooth and lowcost machining. Due to the purely chemical removal the micro structure properties at the workpiece surface remain unaffected. This makes ECM very suitable for the manufacture of temperature sensitive materials such as NiTi-alloys. Nevertheless, in the microscale the size of achievable structures is limited by the size of the electrode, which itself has to be manufactured in advance [9].

One process that unifies the advantages of laser and electrochemical machining is the laser chemical machining (LCM). Within this process the laser beam heats up the workpiece, which is immersed in a continuously pumped electrolyte [10]. Depending on the laser parameters such as the laser power and spot diameter, the induced thermal heating of the workpiece surface can shift the electrochemical potential to the transpassivation region, in which the anodic material dissolution is enhanced. This laser-activated chemical dissolution was observed for different self-passivating metals e.g. stainless steel and titanium alloys [11]. Within suitable process windows material removal occurs without micro structural changes, significant heat affected zones or recast formation. However, LCM is also labelled through its high sensitivity against small parameter variation due to the limited process window and by the low removal rates (up to $10^{-3} \mathrm{~mm}^{3} / \mathrm{min}$ ) [12]. Further, previous works have shown that the surface roughness depends strongly on the applied scan velocity. The areal roughness $S a$ at the ground of micro cavities machined with velocities $<20 \mu \mathrm{m} / \mathrm{s}$ into the chromecobalt alloy Stellite 21 was found to be $>2 \mu \mathrm{m}[13,14]$, whereby at velocities $>1 \mathrm{~mm} / \mathrm{s}$ a polishing effect was demonstrated in titanium resulting in $S a$-values down to $0.1 \mu \mathrm{m}[15]$.

Hence, the combination of low and high scan velocities could increase the surface quality of LCMmachined micro parts. Pursuing a strategy that comprises roughing and finishing steps, the quality of laser chemical machining is characterized and compared with micro milling taking the dimensional accuracy, the surface roughness and the impact on the material's micro structure into account. For this reason, square micro cavities exhibiting lengths between $100 \mu \mathrm{m}$ and $400 \mu \mathrm{m}$ and a depth of $60 \mu \mathrm{m}$, representing forming cavities of micro cold forging dies, are machined with both manufacturing technologies into Stellite 21. Subsequently, the geometrical features, the surface roughness as well as the micro structural impact on the surface-near layers are investigated. Furthermore, the machining results are discussed and the process-related limitations are identified.

\section{Methodology}

\subsection{Micro cavity manufacturing}

\subsubsection{Material}

As sample material the cast chrome-cobalt alloy Stellite 21 from "Deloro Wear Solutions GmbH" with the chemical composition $(>60 \% \mathrm{Co}, 27 \% \mathrm{Cr}$, $5.5 \% \mathrm{Mo}, 2.5 \% \mathrm{Ni}$ and $1.5 \% \mathrm{Fe}$ ) was used. On the surface of eroded samples having a diameter of $33 \mathrm{~mm}$ and a thickness of $5 \mathrm{~mm}$, square micro cavities with side lengths between $100 \mu \mathrm{m}$ and $400 \mu \mathrm{m}$ and depths of $60 \mu \mathrm{m}$ were machined using micro milling and laser chemical machining. Fig. 1 shows the targeted dimensions as well the quality parameters to be investigated.
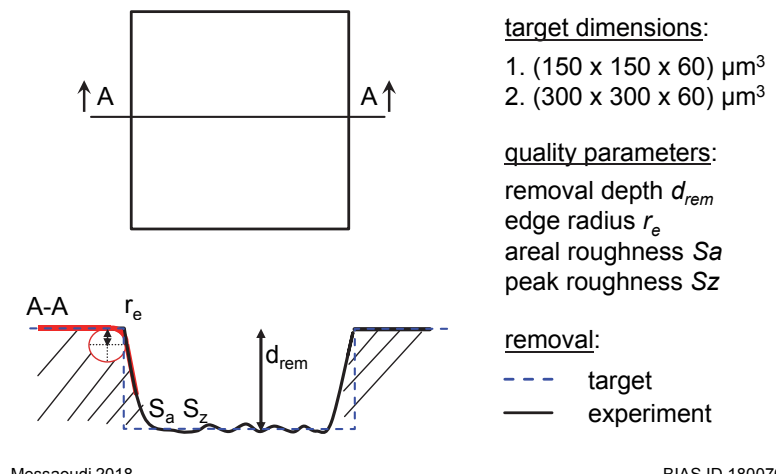

Messaoudi 2018

BIAS ID 180076

Fig. 1. Schematic illustration of the cavity geometry as well as the investigated quality parameters

(a)
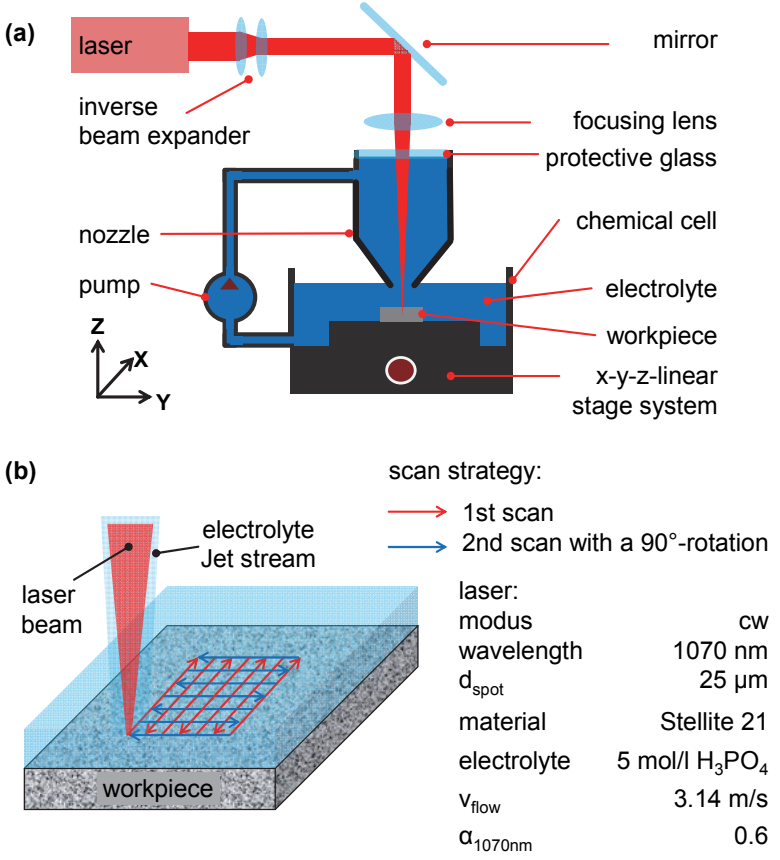

Messaoudi 2018

BIAS ID 180069

Fig. 2. Schematic illustration of the main components for the experimental set up (a) as well as the relevant process parameters for LCM (b). 


\subsubsection{Laser chemical machining}

A cw-fiber laser TruFiber 300 (from Trumpf) was applied as laser source. Its gaussian laser radiation of $1080 \mathrm{~nm}$ is first collimated to a beam diameter of $8 \mathrm{~mm}$, reduced in size up to a value of $2 \mathrm{~mm}$ using an inverse telescope and then focussed using a high aperture lens system (focal length of $50 \mathrm{~mm}$ ). With this system the focal spot size $d_{s p o t}$ could be varied between $25 \mu \mathrm{m}$ and $75 \mu \mathrm{m}$, whereby a laser spot diameter of $25 \mu \mathrm{m}$ was applied within this work. As can be seen in Fig. 2, the electrolyte, a 5 molar $(28.7 \%$ vol. $)$ phosphoric acid solution $\left(\mathrm{H}_{3} \mathrm{PO}_{4}\right)$, is pumped through a $2 \mathrm{~mm}$ wide nozzle that is arranged coaxially to the laser beam with a velocity $v_{\text {flow }}$ of $3.14 \mathrm{~m} / \mathrm{s}$. The propagation of the laser beam through the electrolyte affects the power density due to an identified absorption coefficient of 0.6.

A detailed investigation was performed in order to identify the influence of the relevant process parameters on the removal quality. With respect to the targeted dimensions suitable laser and scan parameters were selected (see Table 1). Thereby, the cavity manufacture consists of two steps. As first step a roughing is applied to achieve the aimed removal depth. In a following step, laser chemical finishing is applied to improve the surface quality. Using the parameters illustrated in Table 1 three cavities of dimensions $(150 \times 150 \times 60) \mu \mathrm{m}^{3}$ and $(300 \times 300 \times 60) \mu \mathrm{m}^{3}$ were manufactured.

Table 1. Summary of the selected parameters for the laser chemical manufacture of the micro cavities

\begin{tabular}{|l|c|c|c|c|c|}
\hline & $\begin{array}{c}P_{L} \\
{[\mathrm{~W}]}\end{array}$ & $\begin{array}{c}v_{\text {scan }} \\
{[\mu \mathrm{m} / \mathrm{s}]}\end{array}$ & $\begin{array}{c}d_{\text {overlap }} \\
{[\mu \mathrm{m}]}\end{array}$ & $\begin{array}{c}n_{\text {scan }} \\
{[-]}\end{array}$ & $\begin{array}{c}t_{\text {process }} \\
{[\mathrm{min}]}\end{array}$ \\
\hline $\begin{array}{l}\text { LCM } \\
\text { Roughing }\end{array}$ & 0.6 & 10 & 6 & 2 & $\begin{array}{c}12: 30, \\
50: 00\end{array}$ \\
\hline $\begin{array}{l}\text { LCM } \\
\text { finishing }\end{array}$ & 0.3 & 50 & 6 & 30 & $\begin{array}{c}37: 30, \\
150: 00\end{array}$ \\
\hline
\end{tabular}

${ }^{*} P_{L}$ : laser power (after the propagation through the electrolyte), $v_{\text {scan }}$ : scan velocity, $d_{\text {overlap }}$ : lateral overlapping, $n_{\text {scan }}$ : scan repetitions, $t_{\text {process: }}$ : processing time

\subsubsection{Micro milling}

Machining of the cavities by micro milling was carried out on a DMG Sauer Ultrasonic 20 linear five-axes machine tool. Equipped with a high speed spindle with spindle speeds up to $41,500 \mathrm{~min}^{-1}$ and direct driven feed systems this machine is well suited for micro milling operations. CAD/CAM-programming was used for tool path generation. For micro machining the procedure of tool path generation is essential to achieve desired shape accuracy and surface finish [16]. To meet the required machining quality, in particular the cavity radii, the tool path generation was carried out with the line pitch $a_{e}$ arranged tangential to the targeted cavity contour.

For all machining operations hard coated tungsten carbide ball-end mills of $0.2 \mathrm{~mm}$ and $0.1 \mathrm{~mm}$ in diameter were used. The spindle speed was kept constant at $40,000 \mathrm{~min}^{-1}$. The machining procedure of a single cavity comprises three roughing and three finishing steps, respectively. The roughing steps were the clearing
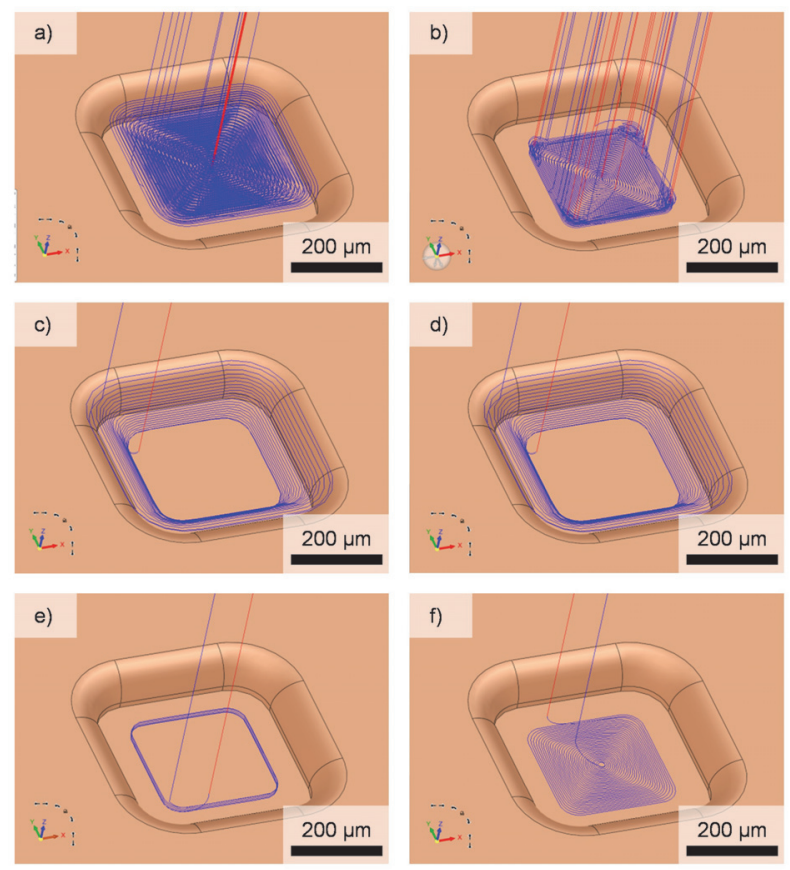

Fig. 3. Tool paths of six consecutive steps for the manufacture of a $(300 \times 300 \times 60) \mu \mathrm{m}^{3}$ micro cavity with an edge radius of $50 \mu \mathrm{m}$ (Screen-shots form CAD/CAD-software); a) clearing of the cavity, b) roughing of the bottom area, c) roughing of the contour of walls and edge radii, d) finishing of the contour of edge radii, e) finishing of the contour of walls, and f) finishing of the bottom area.

of the cavity, roughing of the bottom area, and the roughing of the contour of walls and edge radii, compare Fig. 3. The finishing operation was comprises first: the finishing of the edge radii to a target value of $50 \mu \mathrm{m}$, second: the finishing of the contour of wall and finally the finishing of the bottom area, compare Fig. 3. Material allowance for the finishing cuts was $0.004 \mathrm{~mm}$. Within one experiment five cavities of the same dimension were machined in a row. This allows investigating e.g. the impact of tool wear on the machining results. A detailed overview of all machining operations is given in Table 2.

\subsection{Determination of manufacturing quality}

To examine the manufacturing quality geometrical properties such as removal depth $d_{\text {rem }}$, edge radius $r_{e}$ and shape accuracy were recorded and characterized using a laser scanning confocal microscope (VHX970-Keyence) and a scanning electron microscope (SEM, EVO M10Zeiss).

For the determination of the edge radius a $2 \mathrm{D}$ holistic approximation was used [17]. Based on an algorithm that uses continuous transitions and an automatic separation of the composite geometries measured points of a 2D profile line (cross section of the cavity) are assigned dynamically to the individual control geometries (linecircle-line). The approximation minimizes the orthogonal point distances to these standard geometries according to the L2-norm and iteratively improves the parameters of the composite profiles to fit the measured 
Table 2: Machining steps and associated machining time for the generation of five micro cavities of the dimension $(300 \times 300 \times 60) \mu \mathrm{m}^{3}$ and a radius edge $a_{e}$ of $50 \mu \mathrm{m}$

\begin{tabular}{|c|c|c|c|c|c|c|c|}
\hline $\begin{array}{c}\text { machining } \\
\text { operation }\end{array}$ & tool & tool diameter & feed velocity & depth of cut & width of cut & $\begin{array}{c}\text { material } \\
\text { allowance }\end{array}$ & $\begin{array}{c}\text { machining } \\
\text { time }\end{array}$ \\
\hline $\begin{array}{c}\text { clearing of } \\
\text { the cavity }\end{array}$ & ball-end mill & 0.2 & 150 & 0.005 & 0.005 & 0.006 & $4: 30$ \\
\hline $\begin{array}{c}\text { roughing } \\
\text { bottom area }\end{array}$ & ball-end mill & 0.1 & 25 & 0.004 & 0.004 & 0.004 & $13: 00$ \\
\hline $\begin{array}{c}\text { roughing } \\
\text { walls / radii }\end{array}$ & ball-end mill & 0.1 & 150 & 0.003 & 0.003 & 0.004 & $1: 00$ \\
\hline $\begin{array}{c}\text { finishing } \\
\text { radii }\end{array}$ & ball-end mill & 0.1 & 150 & 0.004 & 0.004 & - & $1: 00$ \\
\hline $\begin{array}{c}\text { finishing } \\
\text { walls }\end{array}$ & ball-end mill & 0.1 & 25 & 0.004 & 0.004 & - & $1: 15$ \\
\hline $\begin{array}{c}\text { finishing } \\
\text { bottom area }\end{array}$ & ball-end mill & 0.1 & 25 & 0.004 & 0.004 & & - \\
\hline
\end{tabular}

profile [18]. In this work, the mean upper edge radius $r_{e}$ of each cavity was determined by approximating 20 profile lines spread over the cavity, half horizontally and half vertically aligned. The profile lines, for which the holistic approximation did not converge, due to e.g. excessive burrs along the edges, were removed from consideration for determining the mean edge radius.

In addition, to identify the influence of the manufacturing method on the micro structure, metallographic investigations were carried out. Therefore, the SEM-records were complemented by an energy dispersive spectroscopic (EDS) analysis to show the chemical composition on selected regions within the cavities. Moreover, metallographic cross-sections of the cavities were prepared to visualize possible thermal effects as well as micro structural changes in the surfacenear layers.

\section{Results}

\subsection{Geometrical properties}

Figure 4 shows exemplarily the captured SEM images of micro milled, laser chemically roughened and finished micro cavities with the targeted dimensions of $(300 \times 300 \times 60) \mu^{3}$. Optically first process-related differences can be identified. The micro milling stands out through its very high finish quality at the cavity ground. In comparison, the LCM roughing results in grossly achieving the cavity dimensions while the LCM finishing provides the final contouring and smoothing of the cavity surface. Moreover, laser chemical machining shows sharper and more accurate contours than micro milling.

The visual impression from Fig. 4 was investigated quantitatively by determining the removal depth $d_{\text {rem }}$ as well as the edge radius $r_{e}$, as depicted in Fig. 5. Both, LCM and micro milling ensured the required depth of $60 \mu \mathrm{m}$ (compare Fig. 5.a). It has to be noticed that the removal depth within the LCM finishing step was increased additionally by about $10 \mu \mathrm{m}$. Thus, the depth
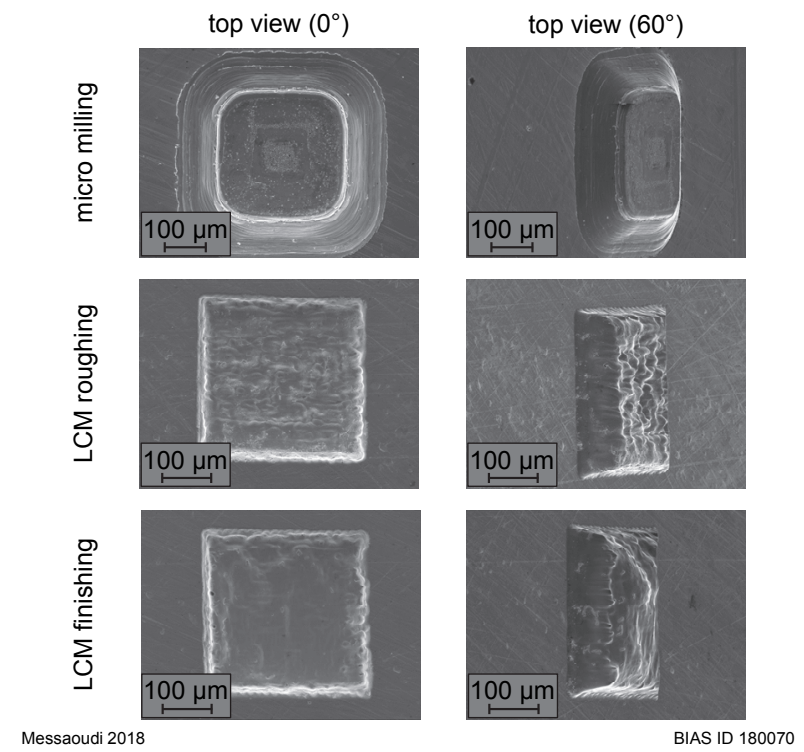

Fig. 4. SEM images of the cavities manufactured using micro milling and laser chemical machining, including the two steps roughing and finishing (top views under $0^{\circ}$ and $60^{\circ}$ )

of the resulting cavities was ranging between $75 \mu \mathrm{m}$ and $78 \mu \mathrm{m}$. Moreover, the depth standard deviation was similar for all methods applied and less than $10 \mu \mathrm{m}$ (see Fig. 4.a).

In addition, results of the 2D holistic approximation (see Sect. 2.2) of the differently manufactured cavities are illustrated in Fig 5.b. The determined mean edge radii confirm the visual impression from Fig. 4 . For both cavity dimensions, the mean edge radii of the cavities manufactured by micro milling are larger than those manufactured by laser chemical machining. This can be explained by the fact that a certain edge radius, whose minimum is determined by the diameter of the used tool, is an essential factor in micro milling. Thereby, the results show that the mean edge radius of the larger micro milled cavities (color-coded in hatched red) with $r_{e}=44.94 \mu \mathrm{m}$ is close to the target value of $50 \mu \mathrm{m}$, which could not achieved for the smaller cavities $\left(r_{e}=23.75 \mu \mathrm{m}\right)$. 
(a)

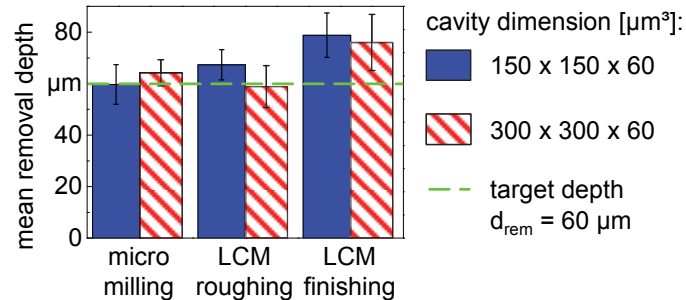

(b)

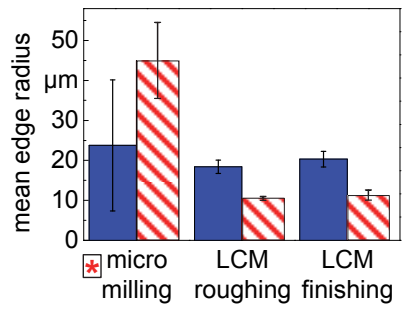

Messaoudi 2018 cavity dimension $\left[\mu \mathrm{m}^{3}\right]$ :

$150 \times 150 \times 60$

N $300 \times 300 \times 60$

target edge radius 头 $\begin{aligned} & \text { target edge radius } \\ & \text { in micro milling is } 50 \mu \mathrm{m}\end{aligned}$

BIAS ID 180071

Fig. 5. Achieved (a) mean cavities depth and (b) mean edge radii of both cavity dimensions in dependence of the applied manufacture method.

In comparison, the edge radii of LCM manufactured cavities are significantly lower. They amount $10.49 \mu \mathrm{m}$ and $11.21 \mu \mathrm{m}$ for roughing and finishing, respectively. Note that the LCM finishing process does not increase significantly the edge radius for both cavity sizes. Comparing the uncertainties of the mean cavity edge radii manufactured by micro milling $(16.4 \mu \mathrm{m})$ with those manufactured with LCM $(1.6 \mu \mathrm{m})$, the former is found to be about an order of magnitude higher in general. This is caused by the wide spread of edge radii for each single manufactured cavity and can be traced back to tool wear and burr formation during the micro milling process at such small dimensions. The increased deviation from the assumed simple edge model of linecircle-line can thus result in different radii regarding the different profile lines within one cavity.

\subsection{Surface quality}

In order to compare the resulting surface quality, the areal surface roughness $S a$ on the cavity ground was determined following the ISO 25178. As depicted in Fig. 6.a, the micro milling shows the higher surface quality with $S a$ values ranging between $0.07 \mu \mathrm{m}$ and $0.3 \mu \mathrm{m}$. In contrast LCM roughing results in $S a>2 \mu \mathrm{m}$, which is clearly reduced during the finishing step down to $0.7 \mu \mathrm{m}$. Thereby, the waviness (Fig. 6.a) has not been totally removed.

To better distinguish between micro and macro roughness, surface features were segmented regarding spatial wavelengths between $0.25 \mu \mathrm{m}$ and $100 \mu \mathrm{m}$. Fig. 6.b shows the characteristic roughness spectra with respect to the machining process. For micro milled cavities, the average roughness is $S a<0.2 \mu \mathrm{m}$ over the complete spatial spectrum, while laser chemical machining is labelled by micro roughness $S a$ of $0.2 \mu \mathrm{m}$ and $0.4 \mu \mathrm{m}$. Further, spatial features between $10 \mu \mathrm{m}$ and
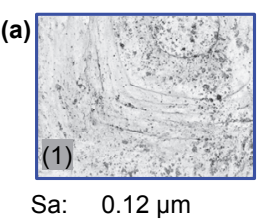

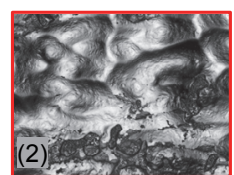

$2.27 \mu \mathrm{m}$ meso-Sa
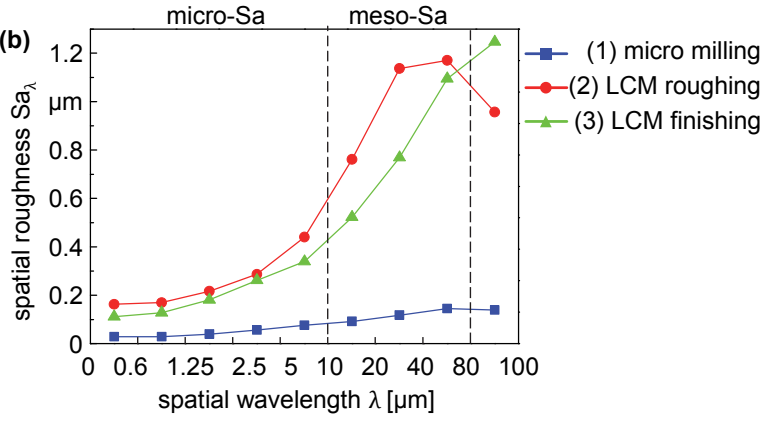

Messaoudi 2018
Fig. 6. Microscopic images of the ground surface of micro milled, LCM roughened as well as a finished cavity (a), and their averaged roughness spectra in dependence of the spatial wavelength (b)

$100 \mu \mathrm{m}$ determine the resulting roughness and explain the higher obtained values for laser chemical machining.

\subsection{Metallographic properties}

To examine possible thermal impacts of micro milling and laser chemical machining on the surface-near layers, cavities cross-sections were prepared. As can be seen in Fig. 7, neither process has a noticeable influence on the micro structure.

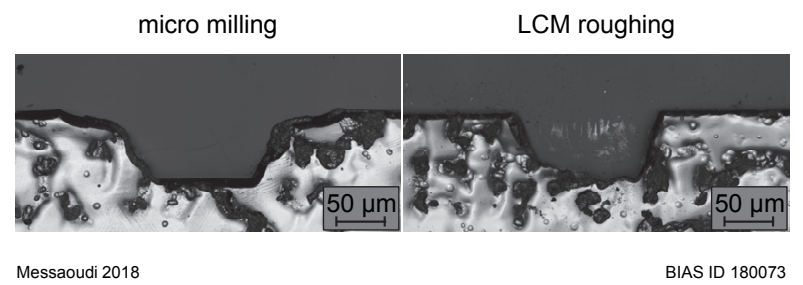

Fig. 7. Microscopic images of transversal cross sections of micro milled and laser chemically roughened cavities

In addition, the chemical composition at different regions from the ground, the walls and the upper borders of selected cavities were analysed by energy dispersive spectroscopy (EDS) and were compared with the base material. The mean values obtained from all measurements are illustrated in Table. 3.

Table 3. Mean values of the atomic mass $\%$ of the element distribution determined from the EDS-analysis

\begin{tabular}{|c|c|c|c|c|}
\hline & $\begin{array}{c}\text { base } \\
\text { material }\end{array}$ & $\begin{array}{c}\text { after micro } \\
\text { milling }\end{array}$ & $\begin{array}{c}\text { after LCM } \\
\text { roughing }\end{array}$ & $\begin{array}{c}\text { after LCM } \\
\text { finishing }\end{array}$ \\
\hline $\mathrm{Co}$ & 61.2 & 52.4 & 48.7 & 59.1 \\
\hline $\mathrm{Cr}$ & 28 & 28.7 & 28 & 28.7 \\
\hline $\mathrm{Mo}$ & 3.6 & 4.9 & 10.7 & 3.2 \\
\hline $\mathrm{Si}$ & 1.3 & 2.1 & 1.4 & 1 \\
\hline $\mathrm{O}$ & 2.2 & 8.5 & 5 & 3.2 \\
\hline $\mathrm{P}$ & 0 & 0 & 2.1 & 0.1 \\
\hline
\end{tabular}


Figure 8 shows the atomic mass of the elements Co, $\mathrm{Mo}, \mathrm{O}$ and $\mathrm{P}$, which were found to be dependent on the machining process. Thereby, an inverse behaviour of Co and Mo has been observed. This is clearly visible in particular during the laser chemical roughing, in which on the one hand $\mathrm{Co}$ is reduced from $61.2 \%$ down to $49 \%$. On the other hand, the amount of Mo is tripled to $10.7 \%$. However, the laser chemical finishing results again in values similar to the base material. Moreover, it removes also the residues of phosphor detected after the roughing step. In contrast, micro milling is characterized by a noticeable increase in oxygen, especially in the bottom radius between ground and wall.
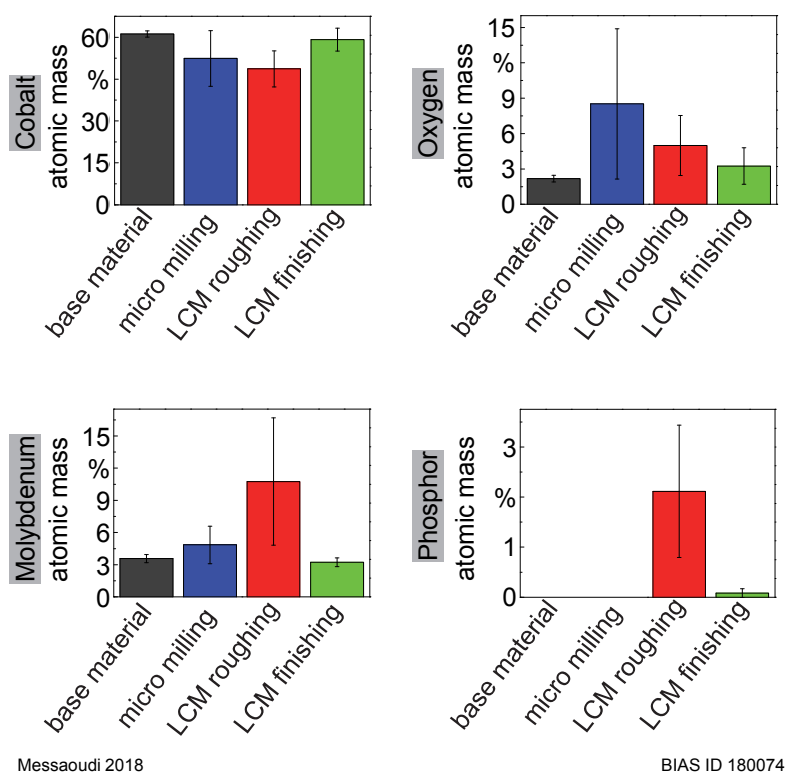

Fig. 8. Determined mean atomic mass distribution of Co, Mo, $\mathrm{O}$ and $\mathrm{P}$ in dependence of the used processing methods.

\section{Discussion}

The comparison of the machining quality of laser chemical machining with micro milling for the manufacture of micro cavities has shown the pros and cons of both processes.

Main advantages of micro milling are the structuring flexibility, especially with five-axes milling, and the wide range of machinable materials. Furthermore, compared to other micro machining processes, micro milling provides relatively high material removal rates, associated with short machining times and economic benefits. In addition, micro milling stands out for its excellent surface finish. Laser scanning confocal measurements applied to the micro cavities allowed to determine mean areal roughness of $S a<0.2 \mu \mathrm{m}$ throughout the complete spatial wavelength spectrum.

However, micro milling faces some major disadvantages. Other than for laser chemical machining, the manufacture of micro cavities by micro milling required for the adaption of the cavities geometries, i.e. the additional realization of corner edge radii of $50 \mu \mathrm{m}$ as part of the cavity's geometry. This is to avoid critical engagement states of the cutting tool at the moment of machining the cavity's corner edge radii, ultimately leading to tool breakage. As displayed in Fig. 9, the required sharp contours of the square geometry could not be machined. Similar limitations are also relevant for the larger cavities (compare Fig. 4).

Generally the achievable edge radius in a cavity is directly dependent on the diameter of the applied tool. The lower limit of diameter of commercially available tools is $50 \mu \mathrm{m}$, what limits the achievable radius to $25 \mu \mathrm{m}$. However, due to decreasing tool stiffness and associated risk of tool breakage, machining with such tools enables only the realization of smallest depth of cut and width of cut. This ultimately leads to a distinct increase of machining time.
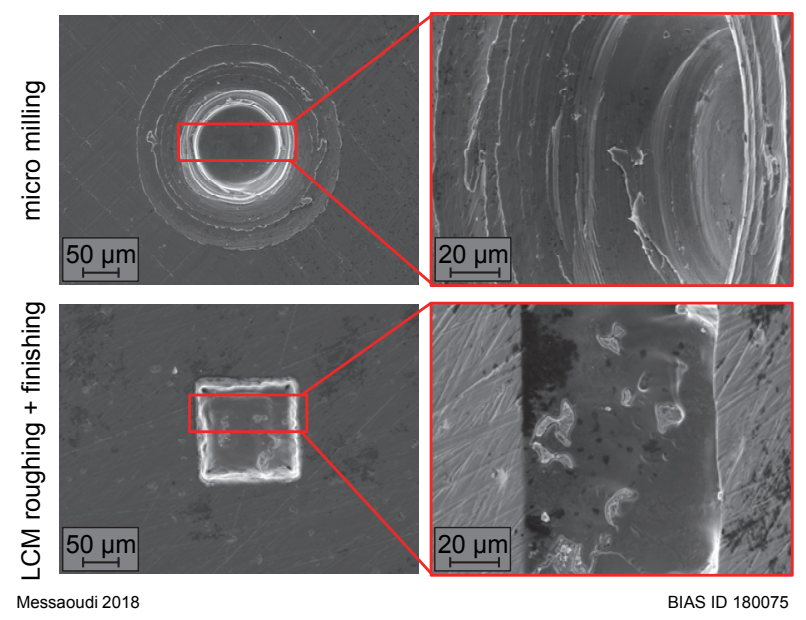

Fig. 9. Top view SEM images of a micro milled (above) and laser chemically machined (below) cavity with targeted dimensions of $(150 \times 150 \times 60) \mu \mathrm{m}^{3}$ as well as under $60^{\circ}$ magnified sections showing the cavity wall.

Furthermore, burr was found on the machined surfaces. This is expected to be a result of local undershooting of the minimum uncut chip thickness accompanied with ploughing of the cutting edge in the workpiece material inadequate material removal. The minimum uncut chip thickness is determined by the properties, i.e. the hardness, of the machined material and the cutting edge radius of the milling tool. For the machining of metallic workpieces of high hardness ( $>50$ HRC) the uncut chip thickness should be at least of the same dimension as the cutting edge radius to ensure adequate chip formation [19]. A new commercially available titanium aluminum nitride (TiAlN) hard coated cemented carbide cutting tool usually exhibits cutting edge radii of about $4 \mu \mathrm{m}$, which equals the values for the width of cut and the depth of cut applied for the finishing procedure. This leads to the conclusion that the minimum uncut chip thickness was not reached at every state of the finishing procedure resulting in the formation of burr. A further increase of width and depth of cut for the applied cutting tools for the presented machining task was not possible due to the limited stiffness of cutting tools of smallest diameter.

Surfaces of the cavities machined by micro milling were subject to an increased presence of oxygen. This indicates thermal loads applied to the workpiece during 
the machining as a result to friction between the flank faces of the cutting edges and the workpiece material. These effects possibly intensify with ongoing wear of the flank faces [20]. However, a negative impact on the surface near work piece material layer, such as crack induction, was not determined after the machining experiments.

In comparison, laser chemical machining has proven its potential and flexibility towards the manufacture of micro metallic parts. It offers the opportunity to use one single tool, the laser beam, that can be varied in its properties (spot size, intensity profile and cw/pulsed mode) much easier compared to micro milling, which necessitates a tool change within the process. This represents an advantage especially in manufacturing micro parts with dimensions $<100 \mu \mathrm{m}$. This can be clearly seen in Fig. 8. The square geometry of the cavity is much sharper than compared with the micro milled one.

Depending on the machining task an enhanced material removal, which is characterized by a poor surface quality, can be assured with slow scan velocities. On this basis the roughing step was realized. Besides, controllable and low removal rates can be realized with increased scan velocities and reduced laser powers. This combination was applied during the ensuing finishing step and led to an improved surface quality. The mean roughness $S a$ was reduced from $>2 \mu \mathrm{m}$ down to $0.7 \mu \mathrm{m}$, while the peak roughness $S z$ from $45 \mu \mathrm{m}$ down to $8 \mu \mathrm{m}$. Further, it has to be noted that surface features with spatial wavelengths $>10 \mu \mathrm{m}$ could not be efficiently removed (compare Fig. 6). Considering the micro roughness (spatial wavelengths $<5 \mu \mathrm{m}$ ), the results show that laser chemical machining is able to achieve values down to $0.2 \mu \mathrm{m}$. The LCM-induced surface irregularities are related to two different effects. The first one is due to the used Gaussian laser beam profile, which results in an inhomogeneous removal even with closed hatching distance [21]. The second effect is related to the unequal chemical dissolution rates of the different alloy elements with respect to the used electrolyte solution [22] as well as the dependence of the achievable surface quality on the micro structure (grain size and element distribution) [15]. Nevertheless, as Fig. 4 shows, the improvement of the quality of the machined cavities as result of LCM finishing step is clearly visible. In accordance with [15], the minimum roughness level is first obtained after a removal depth exceeding the $S z$-values. Knowing that the additional removal depth due to the finishing step was $10 \mu \mathrm{m}$, it is still about $30 \mu \mathrm{m}$ to remove in order to obtain the best surface quality.

In addition, the comparison of the edge radii as well as the cavity walls with micro milling indicates the good dimensional and shape accuracy that LCM can provide. The square geometry with sharp edges and straight sides can be achieved even for dimensions $<100 \mu \mathrm{m}$. Thereby, the upper edge become sharper with an increased cavity dimensions $(18 \mu \mathrm{m}$ for the smaller and $10 \mu \mathrm{m}$ for the bigger cavity size) due to the better conditions for the transport of reaction products and the provision of fresh reactants. Moreover, the cavity walls are much smoother with LCM compared to micro milling, in which the single cutting paths are visible (compare Fig. 9). Thus, a zigzag wall profile as well as a burr formation was obtained. The effect of the burr formation especially on the upper cavity edge was reflected significantly in the higher deviations of the edge radius (see Fig. 5.b).

Furthermore, in view of the machining time it can be seen that micro milling appears much more efficient than laser chemical machining, e.g., $5 \mathrm{~min}$ and $200 \mathrm{~min}$ are needed for the machining of one cavity of $(300 \times 300 \times 60) \mu \mathrm{m}^{3}$, using micro milling and LCM, respectively. However, when considering the tool interaction area $\left(31.5 \cdot 10^{3} \mu \mathrm{m}^{2}\right.$ for the $100 \mu \mathrm{m}$ ball-end mill and $2 \cdot 10^{3} \mu \mathrm{m}^{2}$ for the laser beam), which is about 16 times larger for micro milling, the LCM removal rates are close to those of micro milling. With regard to the tool area the average removal rates within the applied machining conditions amounts to $2.7 \cdot 10^{-5} \mathrm{~mm}^{3} / \mathrm{min}$ for LCM and $6.75 \cdot 10^{-5} \mathrm{~mm}^{3} / \mathrm{min}$ for micro milling.

In summary, laser chemical machining offers higher accessibility and accuracy in the dimension range of $<200 \mu \mathrm{m}$. Nevertheless, it is still challenging to minimize the waviness effect during the roughing procedure. In contrast, micro milling is predestined for the machining of structures with dimensions $>500 \mu \mathrm{m}$. The main quality characteristics of LCM in comparison with micro milling are summarized in Table. 4. Further, it is still providing the better surface finish as well as the more homogeneous material removal. Therefore, a combination of both methods to avoid burr formation and to realize better wall curvature is an approach to follow towards the manufacturing of high-accurate micro metallic parts that can be applied during micro forming applications.

Table 4. Summary of the quality characteristics of laser chemical machining in comparison with micro milling

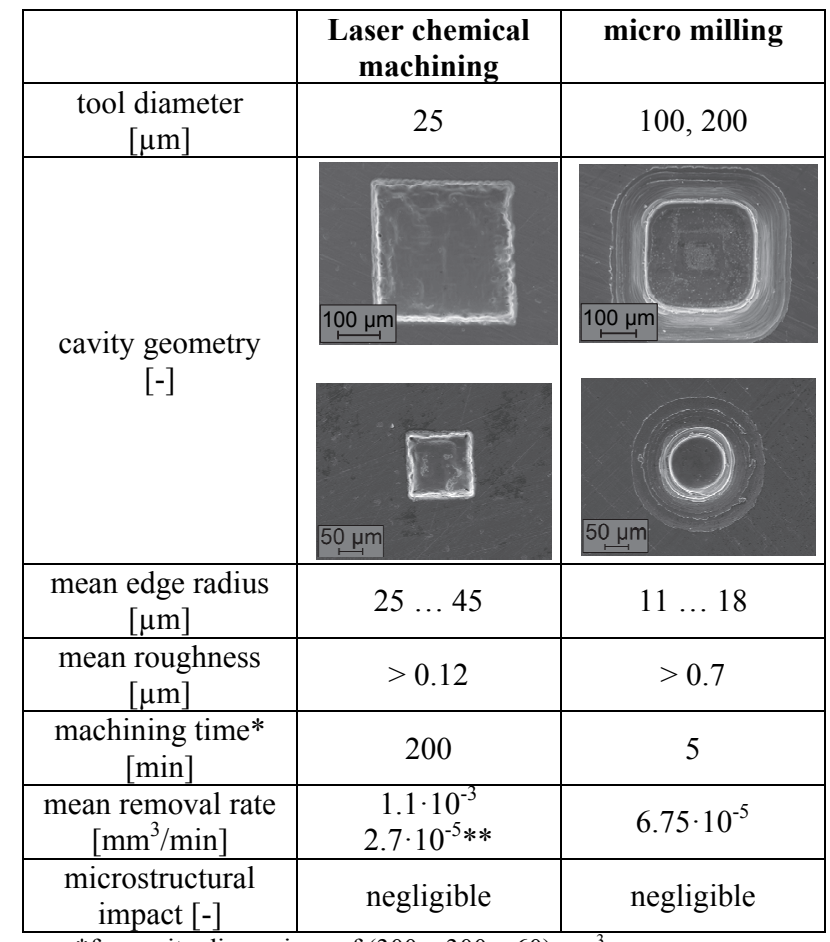

*for cavity dimensions of $(300 \times 300 \times 60) \mu \mathrm{m}^{3}$

**considering equal interaction areas (similar to those of LCM) 


\section{Conclusions}

Laser chemical machining (LCM) consisting of roughing and finishing steps shows higher shape and dimensional accuracy compared with micro milling due to sharp edge contours with mean edge radii of $(11.2 \pm 1.3) \mu \mathrm{m}$. Based on this, LCM is particularly suited for the manufacture of micro cavities with dimensions $<200 \mu \mathrm{m}$. However, the induced surface waviness features (at spatial wavelengths between $20 \mu \mathrm{m}$ and $100 \mu \mathrm{m}$ ) affects the surface quality and limits the process competitiveness with micro milling although small micro roughness of $0.2 \mu \mathrm{m}$.

The authors would like to thank the German Research Foundation (Deutsche Forschungsgemeinschaft "DFG") for funding this work within the sub-projects A5 "Laser Contour", B5 "Reliable Processes" and C2 "Surface Optimization" of the Collaborative Research Centre 747 "Micro Cold Forming Processes, Characterisation, Optimisation" at the University of Bremen. Furthermore, the authors would like to thank Mr. Daniel Brand and Mr. Christian Rösner for their support during the experimental work. Last but not least greatest thanks, too, to Mrs. Denise Loske for her support during the metallographic investigations.

\section{References}

1. M. Geiger, F. Vollertsen, R. Kals, CIRP Annals 45(1), 277-282 (1996)

2. M. Geiger, M. Kleiner, R. Eckstein, N. Tiesler, U. Engel, CIRP Annals 50(2), 445-462 (2001)

3. E. Brinksmeier, A. Schulz, micro metal forming (Springer Verlag), 204-223 (2013)

4. F. Vollertsen, D. Biermann, H.N. Hansen, I.S. Jawahir, K. Kuzman, CIRP Annals 58(2), 566-587 (2009)

5. D. Dornfeld, S. Min, Y. Takeuchi, CIRP Annals 55(2), 745-768 (2006)

6. M.A. Câmara, J.C. Campos Rubio, A.M. Abrão, J.P. Davim, J. Mat. Sci. \& Tech. 28(8), 673-685 (2012)

7. M. Manjaiah, S. Narendranath, S. Basavarajappa, Trans. Nonferrous Met. Soc. China 24(1), 1221(2014)

8. M. Weikert, C. Fohl, F. Dausinger, T. Abeln, SPIE 5063, 208-213 (2003)

9. R.J Leese, A. Ivanov, Adv. Mech. Eng. 8(1), 1-13 (2016)

10. A. Stephen, T. Lilienkamp, S. Metev, G. Sepold, Proc. $1^{\text {st }}$ Int. Conf. EUSPEN (Shaker Verlag), 20-23 (1999)

11. D. Bäuerle, Laser Processing and Chemistry. (Springer Verlag) (2011)

12. A. Stephen, F. Vollertsen, CIRP Annals 59(1), 251254 (2010)

13. H. Messaoudi, O. Hauser A. Matson, S. Mehrafsun, F. Vollertsen, Proc. 8th. Kolloquium Mikroproduktion, 171-178 (2017)
14. P. Zhang, A. von Freyberg, A. Fischer, Int. J. Adv. Manuf. Tech. 93, 3693-3703 (2017)

15. S. Eckert, A. Köhnsen, F. Vollertsen, Proc. Laser in Manufacturing Conference (LIM), 1-8 (2017)

16. E. Brinksmeier, F. Vollertsen, O. Riemer, H. Flosky, G. Behrens, F. Böhmermann, Proc. 6th. Kolloquium Mikroproduktion, 1-8 (2013)

17. K. Lübke, Z. Sun, G. Goch, XXIIII. Messtechnisches Symposium des Arbeitskreises der Hochschullehrer für Messtechnik eV (AHMT), 70-90 (2010).

18. K. Lübke, Z. Sun, G. Goch, CIRP Annals 61(1), 499-502 (2012)

19. A. Aramcharoen, P.T. Mativenga, Precision Engineering 33, 402-407(2009)

20. H.K. Tönshoff, H.-G. Wobker, D. Brandt, HärtereiTechnische Mitteilungen-HTM 50(3), 176-181 (1995)

21. O. Hauser, S. Mehrafsun, F. Vollertsen, $7^{\text {th }}$ Kolloquium Mikroproduktion, 8-14 (2015)

22. F. Klocke, S. Harst, F. Karges, M. Zeis, A. Klink, CIRP Conference on Modelling of Machining Operations 58, 169-174 (2017)

23. S. Eckert, A. Köhnsen, F. Vollertsen, Proceedings of Laser in Manufacturing Conference (LIM), 1-8 (2017) 